\title{
RETRIEVAL OF SEA SURFACE TEMPERATURE OVER POTERAN ISLAND WATER OF INDONESIA WITH LANDSAT 8 TIRS IMAGE: A PRELIMINARY ALGORITHM
}

\author{
M.A. Syariz ${ }^{\text {a }}$ L.M. Jaelani ${ }^{\text {a* }}$, L. Subehi ${ }^{\mathrm{e}}$, A. Pamungkas ${ }^{\mathrm{b}}$, E.S. Koenhardono ${ }^{\mathrm{c}}$, A. Sulisetyono $^{\mathrm{d}}$
}

${ }^{a}$ Dept. of Geomatics Engineering, Faculty of Civil Engineering and Planning; ${ }^{b}$ Dept. of Urban and Regional Planning, Faculty of Civil Engineering and Planning; ${ }^{\mathrm{c}}$ Dept. of Marine Engineering, Faculty of Marine Technology; ${ }^{\mathrm{d}}$ Dept. of Naval Architecture and Shipbuilding Engineering, Faculty of Marine Technology, Institut Teknologi Sepuluh Nopember, Surabaya, 60111, Indonesia.

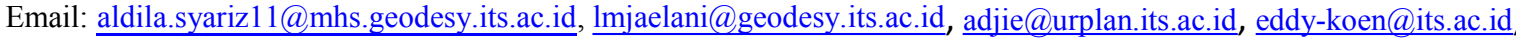
sulisea@na.its.ac.id

${ }^{\mathrm{e}}$ Research Centre for Limnology, Indonesian Institute of Sciences, Cibinong Science Centre, 16911, Indonesia. Email: luki@limnologi.lipi.go.id

KEYWORDS: Sea Surface Temperature, Algorithm, Landsat 8 TIRS, Poteran Island Water

\section{ABSTRACT:}

The Sea Surface Temperature (SST) retrieval from satellites data has been available since 80's both temporally and spatially. Thus, it could provide SST data for a long time. Since, the algorithms of SST estimation by using Landsat 8 Thermal Band are sitedependence, we need to develop an applicable algorithm in Indonesian water. The aim of this research was to develop SST algorithms in the North Java Island Water. The data used are in-situ data measured on April 22, 2015 and also estimated brightness temperature data from Landsat 8 Thermal Band Image (band 10 and band 11). The algorithm was established using 45 data by assessing the relation of measured in-situ data and estimated brightness temperature. Then, the algorithm was validated by using another 40 points. The results showed that the good performance of the sea surface temperature algorithm with coefficient of determination $\left(R^{2}\right)$ and Root Mean Square Error $(R M S E)$ of 0.912 and 0.028 , respectively.

\section{INTRODUCTION}

The coastal sea surface temperature (SST) is one of the important oceanic environmental factors in determining the change of marine environments and ecological activities (Kang et al, 2014). Data with spatial resolution finer than $1 \mathrm{~km}$ have been used to interpret circulation and front movement (Ferrier \& Anderson, 1997).

Remote sensing is an effective approach for estimation of the SST (Qianguo et al., 2005). There are many factors which will influence the accuracy of the SST retrieval (Mao et al., 2004), especially the atmospheric effects. The difficulty of atmospheric correction limits the use of TM/ETM + TIR bands in coastal and inland water (Ritchie and Cooper, 2001; Schott et al., 2001). Some researchers have established SST inversion models depending on the correlation between the TM/ETM + TIR radiance and the in-situ SST data (Chen et al., 2003). Ahn et al. (2006) applied the algorithm by the NASA to the coastal SST retrieval without consideration of the atmospheric effects. The accuracy of SST estimation of these algorithms can range from 0.2 to $3.4^{\circ} \mathrm{C}$ (Thomas et al, 2002). Most importantly, it is usually difficult to apply these algorithms to different atmospheric conditions. Trisakti et al. (2013) developed an algorithm to estimate SST by using the thermal band of Landsat. This model can be applied to obtain SST distribution from data with different seasonal condition in northern and southern water of Java and Bali. But, this is an alternative method in the case of lack of in-situ data.

This research was to develop SST algorithm model from Landsat Thermal Band by using a single time acquisition. The estimated SST would be correlated by in-situ SST.

\section{METHODS}

\subsection{Location}

The study area was at Poteran Island Water, Sumenep, Southeast Madura Island, East Java, Indonesia.

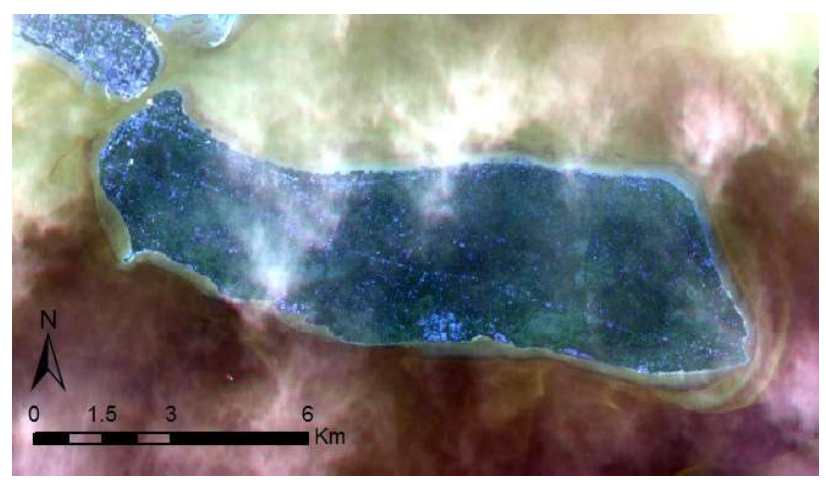

Figure 1. Poteran Island (RGB 432)

Figure 1 shows the island using Landsat 8 RGB Natural Color.

\subsection{Data Collection}

The estimated data was obtained by the Landsat 8 Thermal Infrared Sensor (TIRS). Landsat 8 provides metadata of the bands such as thermal constant, rescaling factor value, etc. shown at table 1,2, and 3 .

\begin{tabular}{|l|c|c|c|c|}
\hline Sensor & $\begin{array}{c}\text { No. of } \\
\text { Bands }\end{array}$ & $\begin{array}{c}\text { Resolution } \\
(\mathrm{m})\end{array}$ & Path/Row & $\begin{array}{c}\text { Acquisition } \\
\text { Date }\end{array}$ \\
\hline OLI & 9 & 30 & \multirow{2}{*}{$117 / 65$} & $\begin{array}{c}\text { April 22, } \\
2015\end{array}$ \\
\hline TIRS & 2 & 100 & \\
\hline
\end{tabular}

Table 1. Metadata of Satellite Image

\begin{tabular}{|c|c|c|}
\hline Thermal Constant & Band 10 & Band 11 \\
\hline K1 & 774.89 & 480.89 \\
\hline K2 & 1321.08 & 1201.14 \\
\hline
\end{tabular}

Table 2. K1 and K2 Value 


\begin{tabular}{|c|c|c|}
\hline Rescaling Factor & Band 10 & Band 11 \\
\hline $\mathrm{M}_{\lambda}$ & $3.3420 \mathrm{E}-04$ & $3.3420 \mathrm{E}-04$ \\
\hline $\mathrm{A}_{\lambda}$ & 0.10000 & 0.10000 \\
\hline
\end{tabular}

Table 3. Rescaling Factor

The digital number of Band 10 and Band 11 were converted to the brightness temperature by using that metadata. First, it had to be converted to radiance by using following formula.

$$
L_{\lambda}=M_{\lambda} x Q_{C a l}+A_{\lambda}
$$

$L_{\lambda}$ is top of atmosphere spectral radiance. $M_{\lambda}$ is band-specific multiplicative rescaling factor. $Q_{C a l}$ is digital number. And $A_{\lambda}$ is band-specific additive scaling factor. (United States Geological Survey, 2013)

Then, converted them to the brightness temperature by using this formula.

$$
T=\frac{K 2}{\ln \left(\frac{K 1}{L_{\lambda}}+1\right)}
$$

$T$ is at-satellite brightness temperature. $K 1$ and $K 2$ are bandspecific thermal conversion constant. (United States Geological Survey, 2013)

The measured data was obtained by using the GARMIN Aqua Map on Wednesday, April 22, 2015. This instrument recorded not only water depth but also sea surface temperature. It recorded 21147 data in total. For this research, we just used 85 points in developing and validating the algorithm. Table 4 shows the statistical attribute of those points. Figure 2 and 3 shows all points and 85 points.

\begin{tabular}{|l|c|c|}
\hline & For development & For validation \\
\hline Total Points & 45 & 40 \\
\hline Mean & 29.92 & 29.90 \\
\hline Maximum & 30.00 & 30.00 \\
\hline Minimum & 29.80 & 29.80 \\
\hline SD & 0.09 & 0.09 \\
\hline
\end{tabular}

Table 4. Statistical Information of in situ data

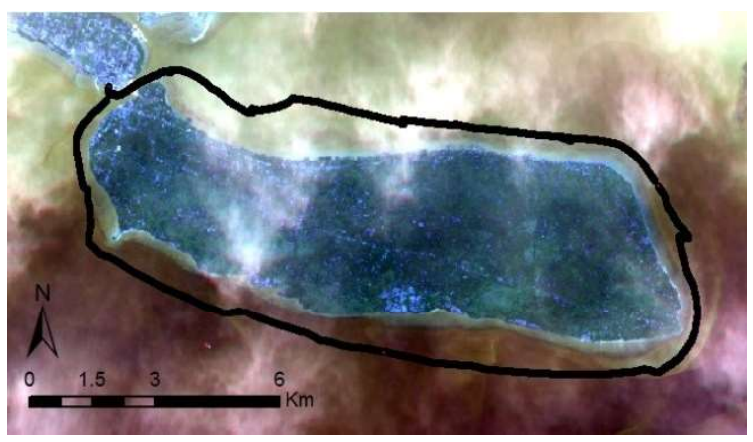

Figure 2. All Points of Measured Sea Surface Temperature

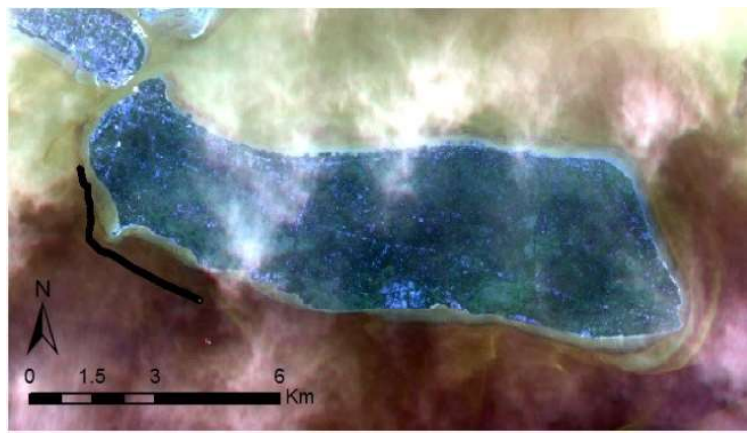

Figure 3. 85 Points for Developing and Validating the Algorithm

\subsection{Statistical Analysis}

To test the accuracy of Landsat 8 Thermal Sensor Brightness Temperature, coefficient of determination $\left(R^{2}\right)$ and Root Mean Square Error (RMSE) were used. The formula of which was shown below.

$$
R^{2}=\left(\frac{n \sum(y)-\left(\sum x\right)\left(\sum y\right)}{\sqrt{n\left(\sum x^{2}\right)-\left(\sum x\right)^{2}} \sqrt{n\left(\sum y^{2}\right)-\left(\sum y\right)^{2}}}\right)^{2}
$$

In the case of developing an algorithm, $x$ is the brightness temperature based on thermal bands of Landsat. But, in validating the algorithm, $x$ is the estimated Sea Surface Temperature. While, $y$ is the measured Sea Surface Temperature.

$$
R M S E=\sqrt{\frac{\sum_{i=1}^{n}\left(X_{e s t i}-X_{\text {meas }}\right)^{2}}{N}}
$$

$X_{\text {esti }}$ is the estimated value of Sea Surface Temperature by the algorithm. $X_{\text {meas }}$ is measured value of Sea Surface Temperature by Garmin Aqua Map. $N$ is total validating points of the algorithm. By using RMSE, we can know how well the algorithm performance

\section{RESULT AND DISCUSSION}

\subsection{Relation of Landsat Thermal Brightness Temperature} and Measured Sea Surface Temperature

Table 5 shows the relationship between Landsat 8 Thermal Sensor Brightness Temperature and Sea Surface Temperature by Garmin Aqua Map. And, that table shows the algorithm of Sea Surface Temperature. Figure 4 and 5 shows the relation graphics of them.

\begin{tabular}{|l|c|c|}
\hline \multirow{2}{*}{$\begin{array}{l}\text { Regression } \\
\text { Model }\end{array}$} & \multicolumn{2}{|c|}{$R^{2}$} \\
\cline { 2 - 3 } & Band 10 BT & Band 11 BT \\
\hline Linear & 0.691 & 0.801 \\
\hline Poly-2 & 0.717 & 0.809 \\
\hline Poly-3 & 0.717 & 0.861 \\
\hline
\end{tabular}

Table 5. Regression Model of Band 10 or Band $11 \mathrm{BT}$ and Measured Sea Surface Temperature
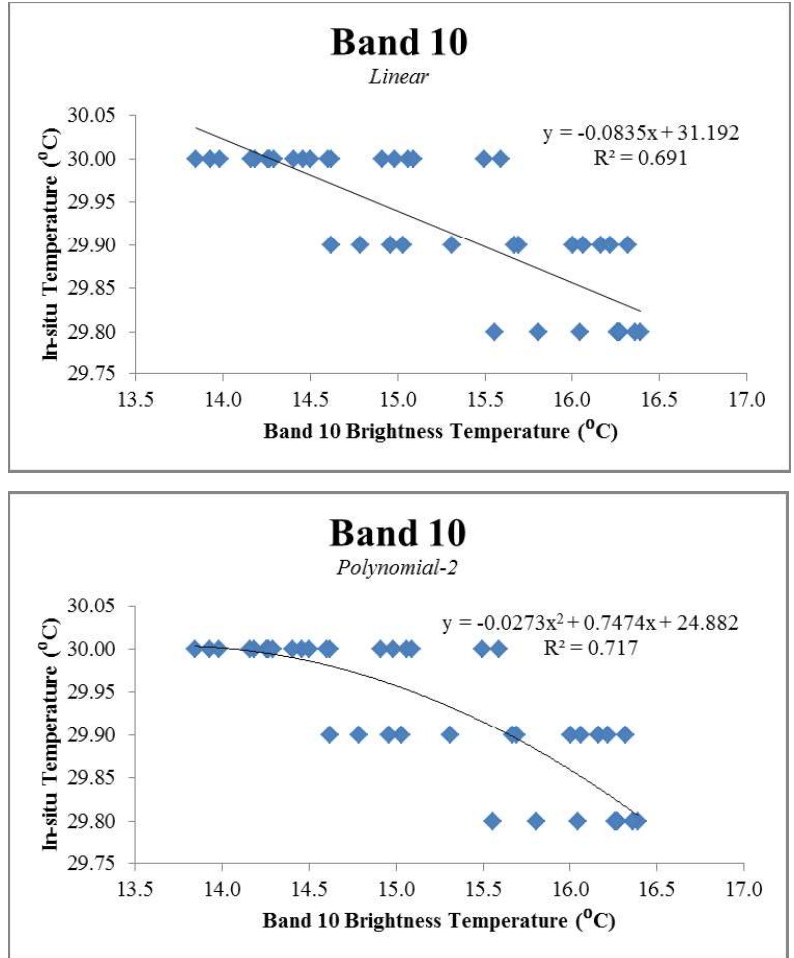


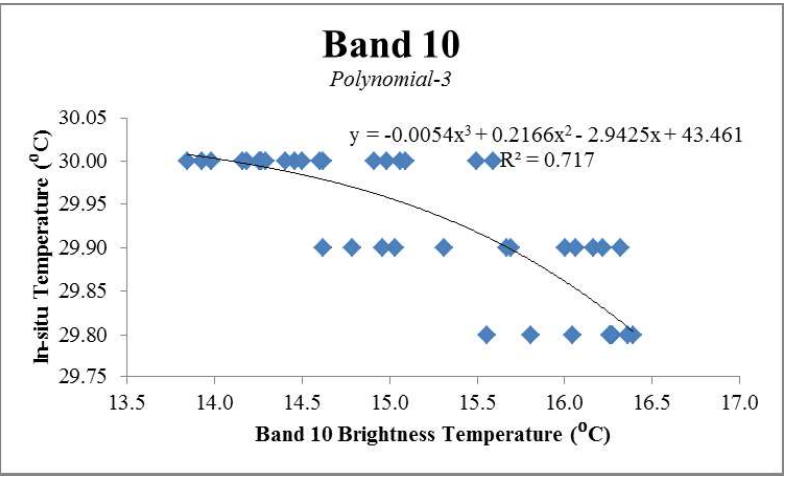

Figure 4. Relation of band 10 BT and Measured Sea Surface Temperature
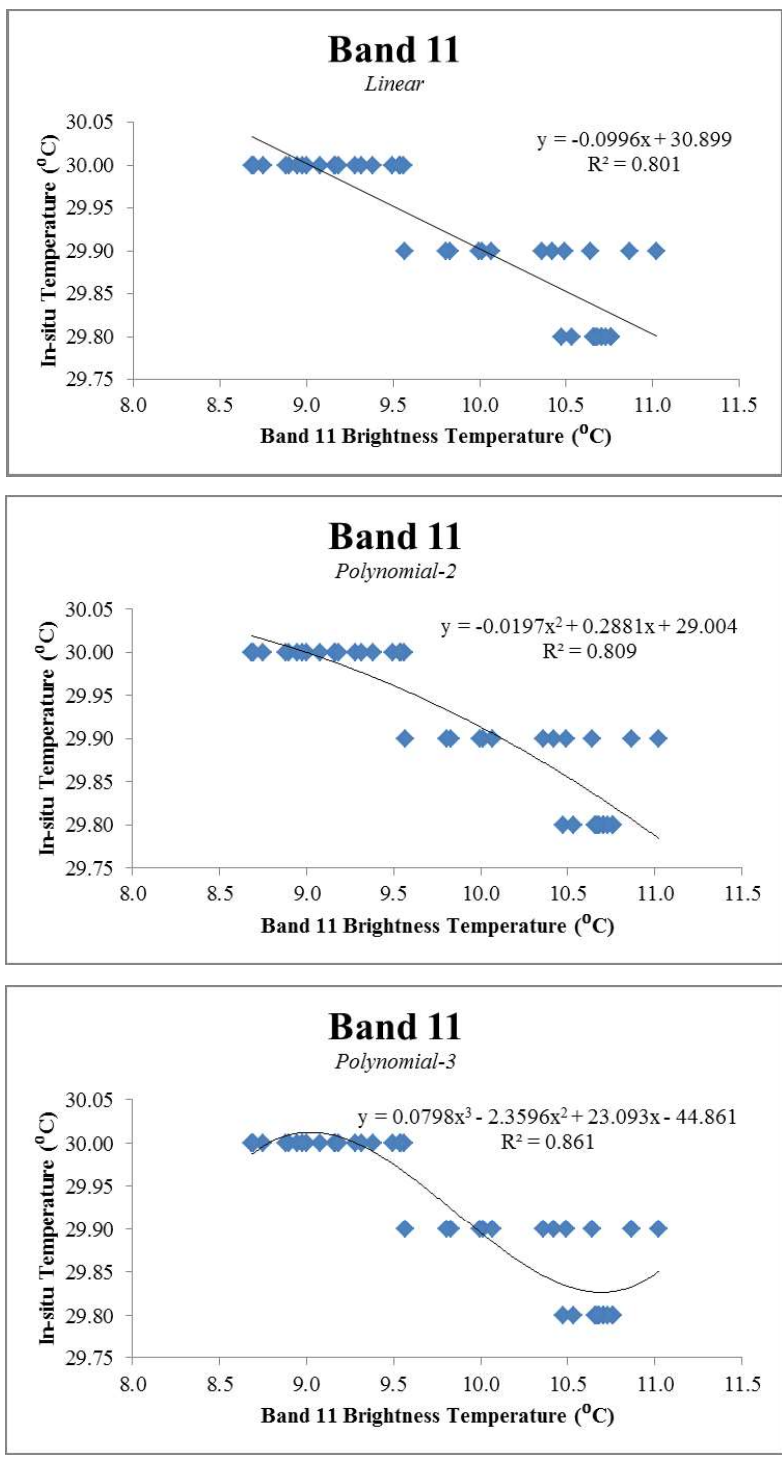

Figure 5. Relation of band 11 BT and Measured Sea Surface Temperature

The brightness temperature and the measured sea surface temperature had a good relation. It could be seen by the value of $R^{2}$ which was above 0.690 .

\subsection{Algorithm Development}

After knew the relationship of Landsat Thermal Sensor Brightness Temperature and Measured Sea Surface
Temperature, we developed an algorithm. Table 6 and 7 shows the TSS retrieval algorithm for band 10 and 11 .

\begin{tabular}{|l|c|c|}
\hline \multirow{2}{*}{$\begin{array}{l}\text { Regression } \\
\text { model }\end{array}$} & \multicolumn{2}{|c|}{ Band 10 Brightness Temperature } \\
\cline { 2 - 3 } & Algorithm & $R^{2}$ \\
\hline Linear & $\mathrm{y}=-0.0835 \mathrm{x}+31.192$ & 0.691 \\
\hline Poly-2 & $\mathrm{y}=-0.0273 \mathrm{x}^{2}+$ & 0.717 \\
& $0.7474 \mathrm{x}+24.882$ & \\
\hline Poly-3 & $\mathrm{y}=-0.0054 \mathrm{x}^{3}+$ & 0.717 \\
& $0.2166 \mathrm{x}^{2}-2.9425 \mathrm{x}$ & \\
& +43.461 & \\
\hline
\end{tabular}

Table 6. SST Algorithm based on Band 10

\begin{tabular}{|l|c|c|}
\hline \multirow{2}{*}{$\begin{array}{l}\text { Regression } \\
\text { model }\end{array}$} & \multicolumn{2}{|c|}{ Band 11 Brightness Temperature } \\
\cline { 2 - 3 } & Algorithm & $R^{2}$ \\
\hline Linear & $\mathrm{y}=-0.0996 \mathrm{x}+30.899$ & 0.801 \\
\hline Poly-2 & $\mathrm{y}=-0.0197 \mathrm{x}^{2}+$ & 0.809 \\
& $0.2881 \mathrm{x}+29.004$ & \\
\hline Poly-3 & $\mathrm{y}=0.0798 \mathrm{x}^{3}-$ & 0.861 \\
& $2.3596 \mathrm{x}^{2}$ & \\
& $+23.093 \mathrm{x}+44.861$ & \\
\hline
\end{tabular}

Table 7. SST Algorithm based on Band 11

Where, $\mathrm{x}$ is the dependence variable and $\mathrm{y}$ is the independence variable. $\mathrm{x}$ is the value of brightness temperature of which bands and $y$ is the estimated value of sea surface temperature.

\subsection{Validation of Algorithm}

After developed an algorithm, we needed to assess the performance by validated it using 40 remaining data points. Table 8 shows the value of $R^{2}$ and RMSE of the algorithms. Figure 6 and 7 shows the graphics of the algorithms validation.

\begin{tabular}{|l|c|c|c|c|}
\hline \multirow{2}{*}{} & \multicolumn{2}{|c|}{ Band 10 Algorithm } & \multicolumn{2}{c|}{ Band 11 Algorithm } \\
\cline { 2 - 5 } & $R^{2}$ & $R M S E$ & $R^{2}$ & $R M S E$ \\
\hline Linear & 0.748 & 0.050 & 0.890 & 0.031 \\
\hline Poly-2 & 0.768 & 0.043 & 0.912 & 0.028 \\
\hline Poly-3 & 0.768 & 0.136 & 0.890 & 0.035 \\
\hline
\end{tabular}

Table 8. Performance of the Sea Surface Temperature Algorithms
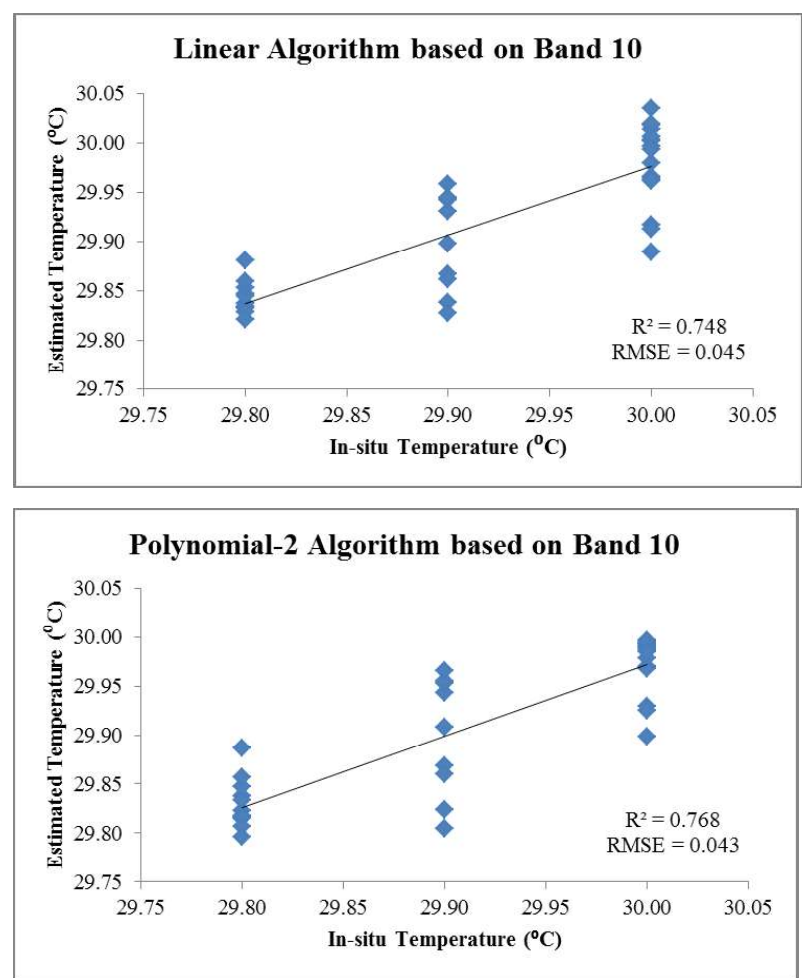


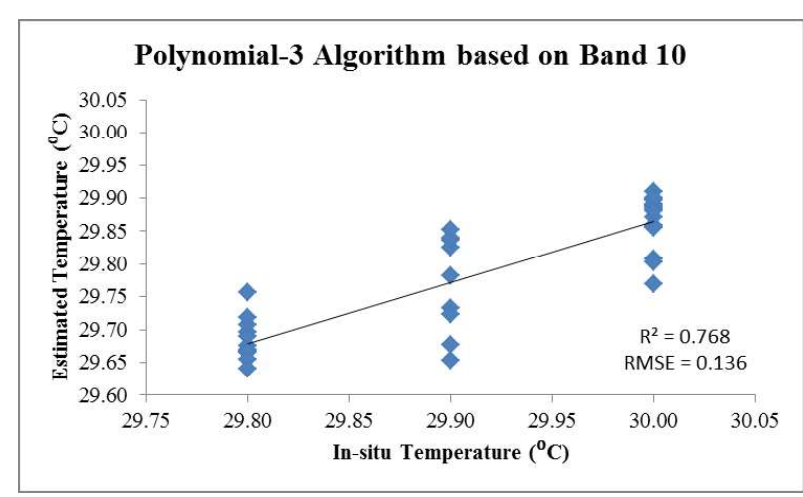

Figure 6. Band 10 Sea Surface Temperature Algorithms Performance
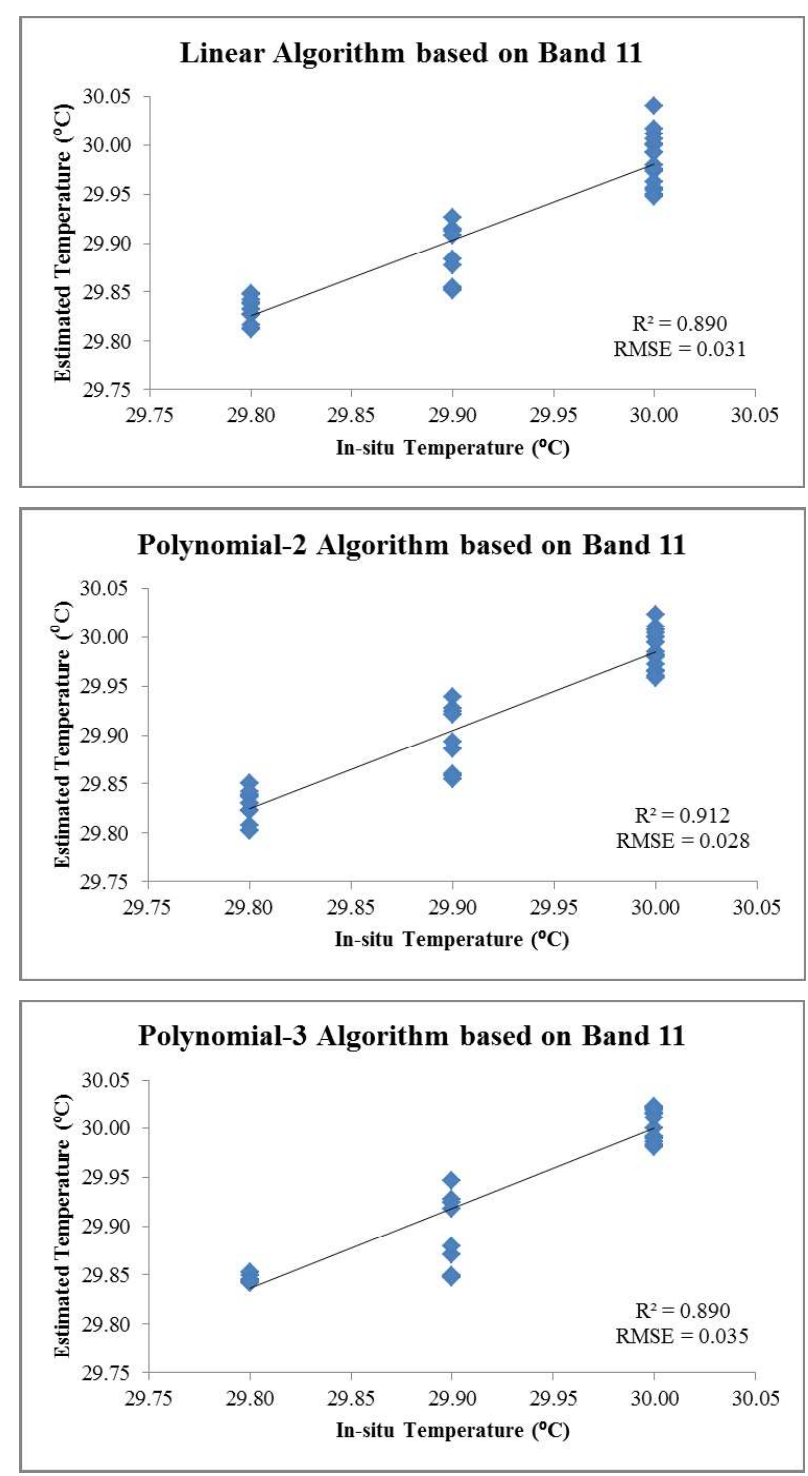

Figure 7. Band 11 Sea Surface Temperature Algorithms Performance

The algorithm based on band 11 polynomial-2 with coefficient of $-0.0197,0.2881$, and 29.004 had a good performance. It could be seen by its $R^{2}$ and $R M S E$ value. The $R^{2}$ is 0.912 and the RMSE is 0.028 .

\section{CONCLUSION}

The Landsat 8 thermal sensor brightness temperature had a good relationship with the measured sea surface temperature. The $R^{2}$ was above 0.600 , the development of algorithms reach the optimum performance if made based on band 10 or 11 . The algorithm based on band 11 polynomial-2 with coefficient of $0.0197,0.2881$, and 29.004 achieved the best performance. Using this algorithm, a routine monitoring of sea surface temperature can be conducted by using satellite data with sufficient accuracy.

\section{ACKNOWLEDGEMENTS}

This research is a part of Sustainable Island Development Initiatives (SIDI) Program, a collaborative research in small island development between Indonesia and Germany.

\section{REFERENCES}

Ahn, Yu-hwan, et al. 2006. Application of Satellite Infrared Data for Mapping of Thermal Plume Contamination in Coastal Ecosystem of Korea. Marine Environmental Research, 61(2), 186-201.

Chen C, Shi P, Mao Q. 2003. Application of Remote Sensing Techniques for Monitoring the Thermal Pollution of Coolingwater Discharge from Nuclear Power Plant. Journal of Environmental Science and Health, Vol. A38(3), Part AToxic/Hazardous Substances and Environmental Engineering, A38(8), pp. 1659-1668.

Kang, Ki-mook, et al. 2014. Comparison of Coastal Sea Surface Temperature derived from Ship-, Air-, and Space-borne Thermal Infrared Systems. International Geoscience and Remote Sensing Symposium, pp. 4419-4422.

Mao, Z, Q. Zhu, D. Pan. 2004. An Operational Satellite Remote Sensing System for Ocean Fishery. Acta Oceanologica, 23(3), pp. 427-436.

Qianguo, Xing, et al. 2006. Atmospheric Correction of Landsat Data for the Retrieval of Sea Surface Temperature in Coastal Water. Acta Oceanologica, 25(3), pp. 25-34.

Ritchie, Jerry C., Charles M. Cooper. 2001. Remote Sensing Technique for Determining Water Quality: Applications to TMDLs. TMDL Science Issues Conference, pp. 367-374.

Schott, John R., et al. 2001. Calibration of Landsat Thermal Data and Application to Water Resource Studies. Remote Sensing Environment, 78(1-2), pp. 108-117.

Thomas, Andrew, Deirdre Byrne, Ryan Weatherbee. 2002. Coastal Sea Surface Temperature Variability from Landsat Infrared Data. Remote Sensing of Environment, 81(2-3), pp. 262-272.

Trisakti, Bambang, Sayidah Sulma, Syarif Budhiman. 2013. Study of Sea Surface Temperature (SST) using Landsat-7 ETM (In Comparison with Sea Surface Temperature of NOAA-12 AVHRR). The Thirteen Workshop of OMISAR, pp. 181-185.

United States Geological Survey. 2013. Using the USGS Landsat 8 Product. http://landsat.usgs.gov/Landsat8_Using_Product.php (29 Jun. 2015. 